\title{
No Cardiac Valve Regurgitation
}

National Cancer Institute

\section{Source}

National Cancer Institute. No Cardiac Valve Regurgitation. NCI Thesaurus. Code C99991.

No evidence of any retrog rade blood flow through the valve(s) in the heart. (ACC) 